\title{
A randomized double-blind clinical trial of the effect of non-absorbable oral polymyxin on infants with severe infectious diarrhea
}

S. Tahan, M.B. Morais, J. Wehba, I.C.A. Scaletsky, A.M.O. Machado, L.Q.C.D. Silva and U. Fagundes Neto
Disciplina de Gastroenterologia Pediátrica, Escola Paulista de Medicina, Universidade Federal de São Paulo, São Paulo, SP, Brasil
Correspondence

M.B. Morais

Rua Pedro de Toledo, 441

04039-031 São Paulo, SP

Brasil

Fax: +55-11-5579-5834

E-mail: mbmorais@osite.com.br

Publication supported by FAPESP.

....................

Received July 11, 2005 Accepted November 21, 2006

\begin{abstract}
The present study evaluated the effect of non-absorbable oral polymyxin on the duodenal microflora and clinical outcome of infants with severe infectious diarrhea. Polymyxin was chosen because classic enteropathogenic Escherichia coli was more sensitive to this antibiotic. Twenty-five infants were randomly assigned to a 7-day treatment with oral polymyxin $(2.5 \mathrm{mg} / \mathrm{kg}$ in 4 daily doses) or placebo. Duodenal and stool cultures were performed before and after the treatment. Five patients were excluded during the study because of introduction of parental antibiotic therapy due to clinical sepsis $(\mathrm{N}=$ 3) or rapid clinical improvement $(\mathrm{N}=2)$. In the polymyxin group, small bowel bacterial overgrowth occurred in $61.5 \%$ of the cases (8/ 13) before treatment and in $76.9 \%(10 / 13)$ after treatment. In the placebo group these values were $71.4 \%(5 / 7)$ and $57.1 \%$ (4/7), respectively. By the 7th day, clinical cure was observed in $84.6 \%$ of the cases (11/13) in the polymyxin group and in $71.4 \%(5 / 7)$ in the placebo group $(\mathrm{P}=0.587)$. Considering all 25 patients included in the study, clinical cure occurred on the 7th day in 12/14 cases (85.7\%) in the polymyxin group and 6/11 cases (54.5\%) in the placebo group $(\mathrm{P}=$ 0.102). Clinical sepsis occurred in $3 / 11(27.3 \%)$ of the patients in the placebo group and in none $(0 / 14)$ in the polymyxin group $(\mathrm{P}=0.071)$. Oral polymyxin was not effective in reducing bacterial overgrowth or in improving the clinical outcome of infants hospitalized with severe infectious diarrhea. Taking into account the small sample size, the rate of cure on the 7th day and the rate of clinical sepsis, further studies with greater number of patients are necessary to evaluate these questions.
\end{abstract}

Key words

- Infants

- Infectious diarrhea

- Duodenal microflora

- Polymyxin

- Sepsis 


\section{Introduction}

Diarrhea raises the levels of infant mortality and is a serious public health problem, though mainly in developing countries. Although oral rehydration therapy significantly reduces the mortality rate of acute diarrhea (1), persistent diarrhea has become increasingly responsible for deaths, especially in infants (2). Victora et al. (3) in Pelotas, RS, Brazil, demonstrated that half of the infants who died from persistent diarrhea were admitted to hospitals during the acute phase of the disease, showing that studies evaluating new therapeutic modalities for hospitalized children with severe diarrhea are necessary.

Enteropathogens such as enteroadherent Escherichia coli, classic enteropathogenic E. coli (EPEC), and Cryptosporidium and Klebsiella spp have been frequently isolated from stool samples of children with persistent diarrhea (4). In São Paulo city and in other urban centers of Brazil, EPEC has been characterized as the main bacterial agent in cases of acute and persistent diarrhea in children, particularly in infants belonging to low income families (5-10). The mechanisms by which these agents associate with persistent diarrhea are not fully understood, though they are perhaps related to the ability of these agents to adhere to and/or invade the intestinal mucosa (1). The events that perpetuate the diarrheal process probably include lesions of the intestinal mucosa, intolerance to disaccharides and proteins in the diet and overgrowth of bacteria of the fecal flora in the small intestine. EPEC is also associated with bacterial overgrowth in the small intestine (11).

At present, it is well established that the basis for the treatment of acute diarrhea involves the replacement of electrolytes and proper nutritional support (12). However, the use of antimicrobial agents may potentially have favorable effects on the elimination of enteropathogenic agents and, consequently, on the cure of diarrhea. For ex- ample, an expert group has recommended the use of antimicrobial therapy in selected circumstances such as EPEC diarrhea with a prolonged course (13). However, few wellcontrolled studies have evaluated the effect of antibiotics on the treatment of these patients (12,14-16). Studies employing gentamicin to treat children with persistent diarrhea have reported conflicting results (1416). Alam et al. (12) demonstrated that the trimethoprim-sulfamethoxazole combination reduced the duration of diarrhea and the number of hospital infections in infants hospitalized with persistent diarrhea.

The present study evaluated the effect of a non-absorbable oral antibiotic on the duodenal microflora and on the clinical outcome of infants hospitalized with severe infectious diarrhea for at least 7 days.

\section{Patients, Material and Methods}

This 7-day randomized double-blind study focused on clinical characteristics, nutritional evaluation, and analysis of duodenal and stool cultures before and after the administration of polymyxin or a placebo, in infants hospitalized with severe infectious diarrhea.

\section{Medication under study}

Polymyxin was chosen because it is a non-absorbable antibiotic that affects primarily the intestinal lumen (17), acting mainly on enterobacteria, but also moderately against anaerobes (18). The fact that in São Paulo city EPEC is more sensitive to polymyxin than other antibiotics (6) was also taken into consideration. Polymyxin B sulfate was used at the dose of $2.5 \mathrm{mg} / \mathrm{kg}$, which corresponds to $25,000 \mathrm{IU} \mathrm{kg}^{-1} \mathrm{dose}^{-1}$ in 4 daily oral doses.

\section{Sample size}

The statistical power and significance 
level were $80 \%$ and 0.05 , respectively. By the 4 th day of treatment, a $0.85 \%$ cure rate was expected for the treated group and a rate of $0.30 \%$ for the control group. A modified Rosner (19) formula was used and a number of 10 cases per group were calculated, yielding a total of 20 patients. To provide a margin for error, 30 treatments were prepared and randomized.

\section{Treatment allocation}

Polymyxin and placebo were supplied and randomized by the Zambom Laboratory (São Paulo, SP, Brazil). The bottles of both treatment groups looked identical and were sequentially numbered to correspond to the patients' serial numbers and randomization code. Only the statistician, who had no contact with the patients, kept a list with the contents of each numbered vial. The placebo had the same physical, chemical and flavor characteristics as the antibiotic. The identity of the treatment (polymyxin or placebo) was unknown to the investigators until the time of analysis.

\section{Patients and study design}

The period of data collection was from January 1993 to April 1997. The inclusion criterion was diarrhea for at least 7 days in infants with less than one year of age who needed hospitalization. Diarrhea was defined as 3 or more liquid evacuations in the $24 \mathrm{~h}$ preceding the beginning of treatment (20). Exclusion criteria were: 1) infants with associated disorders; 2) use of antibiotic(s) in the 7 days preceding the study; 3 ) patients who did not complete the study protocol (7 days of analysis and duodenal and stool culture collection). Patients who presented evidence of systemic infectious during the study protocol were also excluded from the final analysis, which included duodenal and stool cultures before and after medication. However, considering the principle of intention to treat, the total number of patients who entered the study were included only in the analysis of clinical evolution to sepsis and clinical cure on the 4th and 7th days of treatment.

The study was conducted in the Pediatric Gastroenterology Inpatient Care Unit of the Hospital of São Paulo, Escola Paulista de Medicina, Universidade Federal de São Paulo (UNIFESP-EPM). The source of patients was the Pediatric Emergency room visits where they received fluid and electrolyte replacement therapy for the correction of metabolic disorders. The hospitalization of these patients was necessary to maintain parenteral hydration and/or due to food intolerance. Upon admission the patients were evaluated for the presence of metabolic and hydroelectrolytic disturbances and food intolerance during their stay in the Pediatric Emergency room visits. Food intolerance was defined as the presence of anorexia, vomiting, abdominal distention and/or persistent diarrhea and weight loss (with an adequate caloric supply) associated with fecal $\mathrm{pH}<6.0$ and/or the presence of reducing substances in the stools (21). Patient histories were taken for data such as birth weight and feeding history. Percentiles and $\mathrm{Z}$ scores for weight/age, weight/height and height/ age were calculated using the Epi-Info program, version 6.0 (22), related to the National Center for Health Statistics (23) table for weight and height.

After admission to the study, the patients were randomly assigned to one of the two treatment groups: one group received polymyxin and the other received a placebo.

The clinical course of these patients was analyzed for 7 days (study period) and was based on the following parameters: daily weight gain, disappearance of diarrhea, calories received (orally or parenterally), and $\mathrm{Z}$ scores for weight/age at the beginning and at the end of the study. For the 7 days of the study, the patients received a semi-elemental formula consisting of hydrolyzed protein from cow milk whey, mid-chain triglyceri- 
des, cow milk fat, corn oil, maltose-dextrin, starch, vitamins, and mineral salts. This formula is equivalent to $220 \mathrm{mOsm} / \mathrm{L}$ and 72 kcal/dL (Alfaré, Nestlé ${ }^{\circledR}$, Lousanne, Switzerland).

On the basis of World Health Organization recommendations (2), a clinical cure was defined as the disappearance of diarrhea and the attainment of a weight higher than the one observed at the beginning of the study (2). The proportion rate of clinical cure was evaluated on the 4 th and 7 th days of treatment.

Laboratory evaluation before and after 7 days on medication or placebo, included stool cultures (24), duodenal secretion cultures with tests for aerobic (24) and anaerobic (25) bacteria, and a susceptibility test for antibiotics, including polymyxin for aerobic bacteria (26). Upon admission to the study, tests were performed for rotavirus in stool (27), Giardia lamblia, Entamoeba histolytica (28) and Cryptosporidium in stool (29), and $G$. lamblia trophozoites using freshly obtained duodenal fluid (30). Small bowel bacterial overgrowth (SBBO) was characterized by the presence of any number of aerobic or anaerobic microorganisms common to the flora of the colon, determined by the isolation of a fluid culture from the jejunum $(31,32)$. In the cases that presented bacterial proliferation in the small intestine before treatment, a bacteriological cure was defined as the disappearance of bacterial proliferation in the small intestine by the end of treatment, i.e., after 7 days of medication. Transitory flora, nasopharynx and respiratory tract bacteria were not taken into consideration.

\section{Laboratory tests}

Stool. E. coli strains were isolated on MacConkey agar. Four separate lactose-fermenting colonies, presumed to be $E$. coli by colony morphology, and two non-lactosefermenting colonies of each distinct mor- phologic type were cultivated in EPM and MILi (33) media for biochemical confirmation of the species or genus. All E. coli colonies were submitted to slide agglutination with polyvalent and monovalent antisera (PROBAC do Brasil, São Paulo, SP, Brazil) against $\mathrm{O}$ antigens of EPEC serogroups and enterohemorrhagic $E$. coli. The serogroups considered were as follows: $\mathrm{O} 26$, O55, O86, O111, O119, O125, O126, O127, O128ab, O142, O157, and O158. Shigella spp, Salmonella spp, Yersinia spp were tested by standard methods (24). Rotavirus (27), G. lamblia, E. histolytica (28), and Cryptosporidium (29) were all tested.

\section{Duodenal fluid}

A sterile enteral probe (Peditube ${ }^{\circledR}$, Biosearch Medical Products, Inc., Somerville, NJ, USA) was used to collect duodenal samples. The procedure was always performed in a sterile surgical environment. The collection of duodenal secretions was carried out after a fast of at least $4 \mathrm{~h}$ (34) using a previously described technique (35) which facilitates the manual progression of the probe to the duodenum using a special guide wire. The probe was considered to have reached the duodenum when an aspirate of yellowish digestive fluid of a $\mathrm{pH}$ higher than 6.0 was encountered. The first milliliter aspirated was discarded due to the possibility of probe contamination with oropharyngeal or stomach secretions (34). A 0.5-mL sample was then aspirated into a sterile syringe for the culture of aerobic microbes, another $0.5-\mathrm{mL}$ sample, free of air bubbles, was obtained, for the culture of anaerobes and a final $0.5-\mathrm{mL}$ sample was obtained to test for G. lamblia trophozoites, the fresh liquid being examined with a light microscope (30). The samples were quickly transported to the laboratory for immediate processing. The time spent carrying out the procedures was recorded for all samples. For the anaerobe tests $0.5-\mathrm{mL}$ duodenal as- 
pirate samples, free of air bubbles, were processed for culture and identification of anaerobic bacteria (25). A colony count per milliliter was performed using a colony collection plate that had a greater dilution of collected material. For the aerobe tests 0.5$\mathrm{mL}$ duodenal aspirate samples were processed for the culture and identification of Gram-positive aerobic cocci and Gram-negative aerobic bacteria (24) and colonies were counted by the same procedure as used for the anaerobes. Using the disk diffusion method, the aerobic pathogens isolated from the duodenal secretions were tested for susceptibility to antibiotics, including polymyxin (26).

\section{Statistical analysis}

The Student $t$-test, the Mann-Whitney test, and the one-tailed Fisher exact test were used to compare the variables for the two independent groups.

The calculations were performed using the Epi-Info program, version 6.0 (22) and the Jandel Sigma-Stat (36) program.

\section{Ethical considerations}

The project was approved by the Ethics Committee of the Hospital of São Paulo (UNIFESP-EPM) and informed written consent was obtained from the persons responsible for the infants.

\section{Results}

Initially, 25 patients were included consecutively in the study, but subsequently 5 of them had to be excluded during the study period for the following reasons: introduction of parenteral antibiotic therapy $(\mathrm{N}=3)$ due to clinical sepsis and clinical improvement $(\mathrm{N}=2)$.

At the time of analysis, the opening of the double-blind trial seal revealed that the three patients who presented sepsis had received placebo and of the two patients who presented clinical improvement, one received placebo and the other polymyxin. There were no adverse effects due to the drug employed. Thus, 20 patients completed treatment, 13 of them receiving polymyxin and 7 placebo. None of the patients died. Comparing the 5 patients excluded with the 20 patients who completed the study, there were no statitical significant differences between clinical and laboratorial data (data not shown).

Upon admission, both groups presented similar clinical and laboratory characteristics, as shown in Table 1. All patients $(100.0 \%)$ presented food intolerance, $80.0 \%$ had "severe dehydration" and the majority presented metabolic acidosis and electrolyte imbalances, clear evidence that these patients presented a severe episode of diarrhea.

Table 2 shows the results of the aspirated duodenal cultures and of the stool cultures for the groups studied. If we consider all the patients admitted to the study, the isolation

Table 1. Characteristics of patients upon admission to the study.

\begin{tabular}{|c|c|c|}
\hline & Polymyxin ( $N=14)$ & Placebo $(\mathrm{N}=11)$ \\
\hline Age (months) $)^{1}$ & $4.64 \pm 1.86$ & $3.24 \pm 1.97$ \\
\hline Gender (male/female) ${ }^{3}$ & $9 / 5$ & $8 / 3$ \\
\hline Duration of diarrhea (days) ${ }^{2}$ & $13(7-21)$ & $14(9-18)$ \\
\hline Birth weight $(g)^{1}$ & $2898 \pm 688$ & $2987 \pm 639$ \\
\hline Weaned $(<3 \text { months })^{3}$ & $13(92.8 \%)$ & $11(100 \%)$ \\
\hline Z score for weight/age 1 & $-2.0 \pm 1.1$ & $-1.6 \pm 1.2$ \\
\hline$Z$ score for height/age ${ }^{1}$ & $-1.8 \pm 1.3$ & $-2.0 \pm 1.4$ \\
\hline Z score for weight $/$ height $^{1}$ & $-0.9 \pm 1.0$ & $-0.3 \pm 0.4$ \\
\hline Moderate dehydration ${ }^{3}$ & $2(14.3 \%)$ & $3(27.3 \%)$ \\
\hline Severe dehydration ${ }^{3}$ & $12(85.7 \%)$ & $8(72.7 \%)$ \\
\hline Feeding intolerance ${ }^{3}$ & $14(100 \%)$ & $11(100 \%)$ \\
\hline Metabolic acidosis $(\mathrm{pH}<7.35)^{3}$ & $10(71.4 \%)$ & $8(72.7 \%)$ \\
\hline Electrolyte imbalance 3 & $8(57.1 \%)$ & $5(45.4 \%)$ \\
\hline Hemoglobin $(\mathrm{g} / \mathrm{dL})^{1}$ & $8.7 \pm 1.4$ & $8.8 \pm 2.1$ \\
\hline $\mathrm{SBBO}^{3}$ & $8(57.1 \%)$ & $9(81.8 \%)$ \\
\hline Stool culture positive for enteropathogens ${ }^{3}$ & $9(64.3 \%)$ & $7(63.6 \%)$ \\
\hline EPEC (stools) ${ }^{3}$ & $7(50.0 \%)$ & $7(63.6 \%)$ \\
\hline \multicolumn{3}{|c|}{$\begin{array}{l}\text { Data are reported as mean } \pm \mathrm{SD} \text {, number of patients with percent in parentheses or as } \\
\text { indicated in Table. Electrolytic imbalances considered were: hyponatremia }\left(\mathrm{Na}^{+}<130\right. \\
\mathrm{mEq} / \mathrm{L}) \text {, hypocalcemia }\left(\mathrm{K}^{+}<3.5 \mathrm{mEq} / \mathrm{L}\right) \text {, or hypercalcemia }\left(\mathrm{K}^{+}>6.0 \mathrm{mEq} / \mathrm{L}\right) . \mathrm{SBBO}= \\
\text { small bowel bacterial overgrowth; EPEC = classic enteropathogenic Escherichia coli. } \\
\mathrm{P}>0.05 \text { for comparisons of all parameters between the polymyxin and placebo } \\
\text { groups ( }{ }^{1} \text { Student } t \text {-test, }{ }^{2} \text { Mann-Whitney test, }{ }^{3} \text { Fisher test). }\end{array}$} \\
\hline
\end{tabular}


Table 2. Cultures of stools and duodenal secretion obtained from the patients upon admission and at the end of the study.

\begin{tabular}{|c|c|c|c|c|c|c|}
\hline \multirow{2}{*}{$\begin{array}{l}\text { Group } \\
\text { (Patient No.) }\end{array}$} & \multicolumn{2}{|c|}{ Feces } & \multicolumn{4}{|c|}{ Duodenal secretion } \\
\hline & Initial & Final & Initial SBBO & & Final SBBO & \\
\hline \multicolumn{7}{|l|}{ Polymyxin } \\
\hline 1 & EPEC 0111 & - & EPEC $011110^{9}$ & $\mathrm{Y}$ & $\begin{array}{l}\text { Enterococcus spp } 10^{7} \\
\text { Klebsiella spp } 10^{5}\end{array}$ & Y \\
\hline 2 & - & - & Enterococcus spp $10^{2}$ & $\mathrm{Y}$ & $\begin{array}{l}\text { Enterococcus spp } 10^{3} \\
\text { S. aureus } 10^{1} \\
\text { S. viridans } 10^{1}\end{array}$ & Y \\
\hline 5 & EPEC O111 & - & $\begin{array}{l}\text { EPEC O111 } 10^{9} \\
\text { Peptococcus spp } 10^{3}\end{array}$ & $\mathrm{Y}$ & Nonpathogenic E. coli $10^{3}$ & Y \\
\hline 6 & - & - & $\begin{array}{l}\text { Enterobacter spp } 10^{3} \\
\text { Nonpathogenic E. coli } 10^{3}\end{array}$ & Y & $\begin{array}{l}\text { Enterobacter spp } 10^{3} \\
\text { S. aureus } 10^{3} \\
\text { S. viridans } 10^{3}\end{array}$ & Y \\
\hline 7 & EPEC 0111 & - & EPEC $011110^{7}$ Yeast $10^{4}$ & $\mathrm{Y}$ & Yeast $10^{7}$ & $\mathrm{~N}$ \\
\hline 10 & EPEC O55 & - & $\begin{array}{l}\text { EPEC O26 } 10^{6} \\
\text { Proteus morgani } 10^{4} \\
\text { Klebsiella pneumoniae } 10^{4}\end{array}$ & $\mathrm{Y}$ & Proteus morgani $10^{4}$ & Y \\
\hline 13 & Shiguella sonnei & - & S. viridans $10^{4}$ & $\mathrm{~N}$ & $\begin{array}{l}\text { S. viridans } 10^{4} \\
\text { Bifidobacterium spp } 10^{5}\end{array}$ & Y \\
\hline 14 & EPEC 0111 & - & Nonpathogenic E. coli $10^{2}$ & $\mathrm{Y}$ & $\begin{array}{l}\text { Nonpathogenic E. coli } 10^{2} \\
P \text {. aeruginosa } 10^{2}\end{array}$ & Y \\
\hline 15 & EPEC 0119 & - & S. aureus $10^{2}$ & $\mathrm{~N}$ & S. maltophilia $10^{4}$ & Y \\
\hline 16 & - & - & Yeast $10^{1}$ & $\mathrm{~N}$ & S. maltophilia $10^{4}$ & Y \\
\hline 17 & EPEC 0119 & - & $\begin{array}{l}\text { Nonpathogenic E. coli } 10^{3} \\
P \text {. aeruginosa } 10^{2}\end{array}$ & $\mathrm{Y}$ & $\begin{array}{l}\text { Nonpathogenic E. coli } 10^{2} \\
\text { P. aeruginosa } 10^{2} \\
\text { Bifidobacterium spp } 10^{2} \\
\text { Peptococcus spp } 10^{2}\end{array}$ & Y \\
\hline 18 & - & - & $\begin{array}{l}\text { S. aureus } 10^{3} \\
\text { S. B hemolytic G } 10^{3}\end{array}$ & $\mathrm{~N}$ & $\begin{array}{l}\text { S. aureus } 10^{3} \\
\text { S. B hemolytic } G 10^{3}\end{array}$ & $\mathrm{~N}$ \\
\hline 19 & Shiguella flexneri & - & - & $\mathrm{N}$ & - & $\mathrm{N}$ \\
\hline 23 & - & NP & Propionibacterium spp $10^{4}$ & $\mathrm{~N}$ & NP & NP \\
\hline \multicolumn{7}{|l|}{ Placebo } \\
\hline 3 & - & - & Nonpathogenic E. coli $10^{1}$ & $\mathrm{Y}$ & $\begin{array}{l}\text { Nonpathogenic E. coli } 10^{3} \\
\text { Klebsiella spp } 10^{3}\end{array}$ & $\mathrm{Y}$ \\
\hline 4 & - & - & $\begin{array}{l}\text { Nonpathogenic E. coli } 10^{7} \\
\text { S. aureus } 10^{7}\end{array}$ & $\mathrm{Y}$ & S. aureus $10^{5}$ & $\mathrm{~N}$ \\
\hline 8 & EPEC 0111 & - & Yeast $10^{1}$ & $\mathrm{~N}$ & S. aureus $10^{2}$ & $\mathrm{~N}$ \\
\hline 9 & EPEC 0119 & - & EPEC $011910^{5}$ & $\mathrm{Y}$ & $\begin{array}{l}\text { Nonpathogenic E. coli } 10^{3} \\
\text { S. aureus } 10^{3}\end{array}$ & Y \\
\hline 11 & - & EPEC 0111 & - & $\mathrm{N}$ & Nonpathogenic E. coli $10^{4}$ & Y \\
\hline 12 & EPEC 0111 & - & EPEC $011110^{4}$ & $\mathrm{Y}$ & EPEC $011110^{4}$ & Y \\
\hline 20 & EPEC 0127 & - & $\begin{array}{l}\text { K. pneumoniae } 10^{7} \\
\text { K. oxytoca } 10^{4}\end{array}$ & $\mathrm{Y}$ & S. epidermidis $10^{6}$ & $\mathrm{~N}$ \\
\hline 21 & - & NP & $\begin{array}{l}\text { Pseudomonas spp } 10^{2} \\
\text { S. epidermidis } 10^{5}\end{array}$ & $\mathrm{Y}$ & NP & NP \\
\hline 22 & EPEC 0111 & NP & EPEC $011110^{5}$ & Y & NP & NP \\
\hline 24 & EPEC 055 & NP & $\begin{array}{l}\text { EPEC O55 } 10^{5} \\
\text { Enterobacter spp } 10^{6}\end{array}$ & Y & NP & NP \\
\hline 25 & EPEC 0111 & NP & K. pneumoniae $10^{9}$ & $\mathrm{Y}$ & NP & NP \\
\hline
\end{tabular}

SBBO = small bowel bacterial overgrowth; EPEC = classic enteropathogenic Escherichia coli; $S$. aureus = Staphylococcus aureus; $S$. viridans = Streptococcus viridans; $P$. aeruginosa $=$ Pseudomonas aeruginosa; $S$. maltophilia $=$ Strenotophomonas maltophilia; $S$. B hemolytic $G=$ Streptococcus $B$ hemolytic $G$. Anaerobes in bold print. The duodenal secretion culture result is reported as number of colonies (org/mL). SBBO occurred in 31 of 45 samples of duodenal secretion ( $Y=$ Yes, $N=$ No, NP = not performed). 
of an enteropathogenic agent from the stool cultures was $64.0 \%(16 / 25)$ at the beginning, with EPEC being the main pathogen found, occurring in $56.0 \%$ of cases (14/25), followed by Shigella in $8.0 \%$ of cases $(2 / 25)$. At the end of the study, stool cultures were positive in $5.0 \%(1 / 20)$ of cases, and EPEC was isolated from one patient from the placebo group. The following EPEC serogroups were isolated from stool samples and are listed in decreasing order of frequency: O111 $(\mathrm{N}=8), \mathrm{O} 119(\mathrm{~N}=3), \mathrm{O} 55(\mathrm{~N}=2)$, and O127 ( $\mathrm{N}=1)$. Rotavirus, Cryptosporidium, E. histolytica, and G. lamblia were not found in any patient.

The aspirated duodenal cultures were positive in $93.3 \%$ of the samples (42/45), with aerobic microorganisms in $84.4 \%$ (38/ 45 ) and anaerobic microorganisms in $8.9 \%$ (4/45). Transitory flora was found in $24.4 \%$ $(11 / 45)$ and was associated with coliforms in $13.3 \%$ (6/45). SBBO occurred in 68.8\% (31/ $45)$ of the samples. Among the aerobic coliforms, E. coli was the bacterium most commonly isolated, occurring in 20/45 (44.4\%) of the samples, followed by Klebsiella, in $11.1 \%$ (5/45), and Enterococcus and Enterobacter in 6.7\% (3/45). EPEC was isolated from $20.0 \%(9 / 45)$ of the duodenal aspirate samples, found in 8 of the samples at the beginning of the study and in one at the end. The following serogroups were present: O111 ( $\mathrm{N}=6), \mathrm{O} 119(\mathrm{~N}=1), \mathrm{O} 55(\mathrm{~N}=$ $1)$, and $\mathrm{O} 26(\mathrm{~N}=1)$.

The susceptibility test (by the disk diffusion method) for aerobic microorganisms revealed that all the Gram-negative bacteria (including pathogenic and nonpathogenic $E$. coli) were sensitive to polymyxin.

At the end of the study, there was no statistical difference between the polymyxin and placebo groups that completed the study regarding the following parameters: average calories received (over the 7 days), average weight gain (over the 7 days), difference in weight/age $\mathrm{Z}$ score, percentage weight gain (over the 7 days), persistence of diarrhea (in days during the test period of 7 days), and clinical cure on the 4 th $(P=0.651)$ and 7 th $(P$ $=0.587$ ) days of treatment (Table 3 ).

Table 4 shows the evolution to sepsis during the study period and clinical cures on the 4th and 7th days of treatment, considering all the 25 patients included in the study. There was no statistical difference $(\mathrm{P}=0.647)$ between the polymyxin group $(35.7 \%)$ and the placebo group (36.4\%) on the 4th day of treatment. The polymyxin group presented a higher fraction of clinical cures on the 7 th day of treatment $(85.7 \%)$ than the placebo group $(54.5 \%)$, however, this difference was not statistically significant $(\mathrm{P}=0.102)$. Among all patients included in the study, the evolution to systemic infection (clinical sepsis) occurred in $3 / 11(27.3 \%)$ patients in the placebo group during the 7-day study period and in no patient in the polymyxin group.

Table 3. Clinical course of the polymyxin and placebo groups that completed the study.

\begin{tabular}{|c|c|c|}
\hline & Polymyxin $(N=13)$ & Placebo $(\mathrm{N}=7)$ \\
\hline $\begin{array}{l}\text { Mean calories received from the } \\
1 \text { st to the } 7 \text { th day }\left(\mathrm{kcal} \mathrm{kg}^{-1} \text { day }^{-1}\right)^{1}\end{array}$ & $123.2 \pm 36.7$ & $128.6 \pm 30.7$ \\
\hline Mean weight gain from 1 st to 7 th day $(\mathrm{g})^{1}$ & $371.5 \pm 267.3$ & $275.7 \pm 243.6$ \\
\hline$\Delta \mathrm{Z}$ weight/age ${ }^{1}$ & $+0.278 \pm 0.267$ & $+0.091 \pm 0.323$ \\
\hline$\% \Delta$ weight 1 & $8.47 \pm 6.15$ & $6.06 \pm 5.54$ \\
\hline Duration of intravenous hydration (days) ${ }^{2}$ & $3.0(0-5.0)$ & $4.0(0-6.2)$ \\
\hline Duration of diarrhea (days) ${ }^{2}$ & $4.0 \pm 1.87$ & $3.8 \pm 2.34$ \\
\hline Clinical cure $(4 \text { th day })^{3}$ & $4(30.8 \%)$ & $3(42.8 \%)$ \\
\hline Clinical cure $(7 \text { th day })^{3}$ & $11(84.6 \%)$ & $5(71.4 \%)$ \\
\hline
\end{tabular}

Data are reported as mean $\pm S D$, number of patients with percent in parentheses or as indicated in Table.

$P>0.05$ for comparisons of all parameters between the polymyxin and placebo groups ('Student $t$-test; ${ }^{2}$ Mann-Whitney test; ${ }^{3}$ Fisher test).

Table 4. Clinical course of the polymyxin and placebo groups considering the total number of patients who entered the study.

\begin{tabular}{lcc}
\hline & Polymyxin $(\mathrm{N}=14)$ & Placebo $(\mathrm{N}=11)$ \\
\hline Sepsis evolution during the study period & $0(0.0 \%)$ & $3(27.3 \%)$ \\
Clinical cure (4th day) & $5(35.7 \%)$ & $4(36.4 \%)$ \\
Clinical cure (7th day) & $12(85.7 \%)$ & $6(54.5 \%)$ \\
\hline
\end{tabular}

Data are reported as number of patients and percent in parentheses.

$\mathrm{P}>0.05$ for comparisons between the polymyxin and placebo groups (Fisher test). 
Fisher's test showed a P value equal to 0.072 .

Comparative statistical analysis of the laboratory characteristics between the polymyxin and placebo groups at the beginning and the end of the study did not reveal any significant differences regarding the following parameters: bacterial proliferation in the small intestine, positive stool culture, and presence of EPEC (fecal and duodenal aspirate; Table 5). The time needed for the collection of duodenal aspirate was similar for the polymyxin and placebo groups. The median time was $30.0 \mathrm{~min}$ and the maximum time was $70.0 \mathrm{~min}$.

\section{Discussion}

It is well established that antimicrobial therapy usually is not recommended for children with diarrhea. However, antimicrobials may be useful in reducing associated enteric symptoms, including watery diarrhea and/or dysentery or fever in the more severe cases of illness and in the management of persistent diarrhea (37). The studies of Bartlett et al. (15) and Bhatnagar et al. (16), both of them controlled, demonstrated respectively the lack of clinical efficacy of gentamicin in children with persistent diarrhea in the community and in hospitalized patients with mild to moderate cases of diarrhea. Our study confirms the lack of efficacy of antibiotics in the treatment of diarrhea as observed in those

Table 5. Initial and final laboratory characteristics of the polymyxin and placebo groups.

\begin{tabular}{lcc}
\hline Laboratory characteristics & Polymyxin $(\mathrm{N}=13)$ & Placebo $(\mathrm{N}=7)$ \\
\hline Initial SBBO & $8(61.5 \%)$ & $5(71.4 \%)$ \\
Final SBBO & $10(76.9 \%)$ & $4(57.1 \%)$ \\
Positive initial stool culture & $9(69.2 \%)$ & $4(57.1 \%)$ \\
Positive final stool culture & $0(0 \%)$ & $1(14.3 \%)$ \\
Initial EPEC & $7(53.8 \%)$ & $4(57.1 \%)$ \\
Final EPEC & $0(0 \%)$ & $2(28.6 \%)$ \\
\hline
\end{tabular}

$\mathrm{SBBO}=$ small bowel bacterial overgrowth; EPEC = classic enteropathogenic Escherichia coli present in the stool and in the duodenal aspirate.

$\mathrm{P}>0.05$ for comparisons of all parameters between the polymyxin and placebo groups (Fisher test). studies $(15,16)$. Addionally, we analyzed patients with severe diarrhea, most of them in their first semester of life, characteristic that differentiates our study from the previous ones $(15,16)$. Bhatnagar et al. (16) studied children aged 3 months to 4 years and Bartlett et al. (15) studied children aged 3-35 months.

It should be emphasized that exclusive breast-feeding may decrease the risk of acute and persistent diarrhea, since human milk has protective properties against diarrhea such as avoidance of exposure to bacteria, antimicrobial agents, anti-inflammatory and immunomodulating factors and promotion of healthy microflora (4). Almost all (24/25, $96.0 \%$ ) of our patients were weaned before 3 months of life and all of them were receiving non-human milk on admission to the study. This fact may have probably contributed to severe infectious diarrhea and to the bacterial overgrowth that occurred in our patients.

All of our patients presented food intolerance and dehydration, and most of them presented metabolic acidosis and electrolyte imbalances. Although infants with severe acute diarrhea were included, all were cases of more than 7 days of duration and required hospitalization, thus demonstrating the persistent tendency of the cases. Most episodes of acute diarrhea resolve within 7 days and progressively smaller proportions persist beyond 14, 21, or 29 days. The delineation of persistent diarrhea as a subgroup distinct from acute diarrhea is, as such, arbitrary.

In our study, clinical sepsis and the need for parenteral antibiotics were greater in the placebo group $(27.3 \%)$ than in the polymyxin group $(0.0 \%, \mathrm{P}=0.07)$. Alam et al. (12) also suggested that antibiotic therapy can play a preventive role against hospital infections, since infections occurred in $37.0 \%$ of the placebo group and in only $3.6 \%$ of the trimethoprim-sulfamethoxazole group $(\mathrm{P}=$ $0.03)$.

In the present study, no statistical difference was found in the percentage of cure on 
the 4th day of treatment between the polymyxin group (30.8\%) and the placebo group $(42.8 \%)$, results similar to those reported by Bhatnagar et al. (16) and Bartlett et al. (15). On the other hand, Alam et al. (12) reported a higher proportion of significant therapeutic success (cessation of diarrhea with 7 days of treatment) in the trimethoprim-sulfamethoxazole group $(82.1 \%)$ than in the placebo group $(55.5 \%)$. On the 7 th day, our study showed a cure rate of $84.6 \%$ for the polymyxin group and of $71.4 \%$ for the placebo group $(\mathrm{P}=0.58)$.

There was no difference in the mean number of calories received (cal kg-1 day ${ }^{-1}$ ) between the polymyxin $(123.2 \pm 36.7)$ and placebo groups $(128.6 \pm 30.7)$. The polymyxin group presented a higher weight gain $(371 \pm 267 \mathrm{~g})$ than the placebo group $(276 \pm$ $244 \mathrm{~g}$ ), although the difference was not statistically significant. Perhaps the patients in the polymyxin group presented a greater potential for recovery with the administration of nutritional therapy, since they had a greater weight deficiency at the beginning of the study.

Infection with EPEC is one of the main risk factors associated with death in children with diarrhea. When the clinical features of diarrhea caused by EPEC are compared to those caused by other pathogens, children with EPEC are more likely to fail oral rehydration therapy, have intolerance to cow's milk, require hospitalization, and develop persistent diarrhea (38). EPEC was the main enteropathogenic agent isolated from the feces $(56.0 \%)$ of the patients admitted to our study and in $20.0 \%$ of these cases it was also found in the duodenal fluid. Serogroups O111 and O119 predominated, as has occurred classically in the city of São Paulo (7). There was no statistical difference in EPEC positivity between the placebo and polymyxin groups at the end of the study.

In the present study, rotavirus was not identified, probably because the population studied was of low-socioeconomic status and mostly aged less than 6 months.

Since SBBO is one of the perpetuating factors of diarrhea, most investigators consider the use of antibiotics against persistent diarrhea to be generally justified. However, the present study was the first to carry out duodenal secretion cultures before and after the administration of antibiotic therapy or placebo, analyzing the clinical and bacteriological cures of the SBBO cases. Some studies in this area of research have not investigated the duodenal microflora $(12,14)$ while others have, but only before administering medication $(15,16)$. In addition, the patients who used antibiotics in the 7 days preceding the protocol were not included in our study, in contrast to the study by Bhatnagar et al. (16), which included patients who had received or not prior antibiotic therapy.

Bhatnagar et al. (16) employed qualitative and quantitative criteria in the characterization of SBBO. Bartlett et al. (15) employed quantitative and qualitative criteria independent of the presence of fecal coliforms. We considered the presence of fecal coliforms in the duodenal aspirate as a criterion for the presence of SBBO, regardless of the total bacterial count. Two previous studies, one of which was carried out by our group, found a predominance of enterobacteria in the duodenal aspirate of children with diarrhea, while the Gram-positive cocci predominated in the control group $(31,32)$. It is worth mentioning that our patients presented shorter median intubation times (30.0 $\mathrm{min}$ ) in relation to the maximum allowed time $(4 \mathrm{~h})$, considered to be safe for the diagnosis of SBBO (31).

E. coli was the aerobic coliform most frequently isolated from the duodenal aspirate $(44.4 \%)$, similar to the findings of previous studies $(31,34)$, followed by Klebsiella spp $(11.1 \%)$, also frequently found in other studies $(11,32)$. Since bacteria such as $E$. coli have been frequently isolated from the duodenal aspirate of children with persistent diarrhea, antibiotics employed to act against 
SBBO should present a spectrum of action for these pathogens.

Thóren et al. (39), in 1980, upon finding significant differences in the antibiotic treatment of children hospitalized with diarrhea caused by EPEC, suggested the use of antibiotics chosen for local conditions. Polymyxin did not interfere with SBBO and it is difficult to explain why 3 patients in the polymyxin group presented SBBO only at the end of the study. Besides, the spectrum of action of polymyxin was adequate, since all the Gram-negative bacteria, including pathogenic and non-pathogenic E. coli, were sensitive to this antibiotic in vitro. Furthermore, resistance to gentamicin did not explain the therapeutic failure in the studies of Bhatnagar et al. (16) and Bartlett et al. (15), since both reported that the isolated pathogens presented in vitro susceptibility to this drug.

Considering the principle of intention to treat and all the patients who entered the present study, there was a greater proportion of clinical cure on the 7th day of treatment in the polymyxin group, but the difference was not significant, perhaps due to our small sample size. It is difficult to explain the lower prevalence of clinical sepsis in the group that received polymyxin than in the placebo group. Perhaps this non-absorbable antibiotic prevented bacterial translocation. This hypothesis should be tested since children with persistent diarrhea present almost 30 to $40 \%$ of associated systemic infections (40). However, the role of antibiotics in this clinical condition has not been evaluated previously.

Taking into account the small sample size and the rate of cure on the 7th day and the rate of clinical sepsis, we understand that further studies with greater sample size should evaluate these questions. The decrease in the incidence of infant attended with diarrhea in our hospital does not allow to perform this kind of study.

In conclusion, it is important to emphasize that, in spite of the persistence of bacterial overgrowth in the small intestine, both groups in our study presented satisfactory clinical and weight evolution, a fact that reinforces the importance of nutritional therapy in the treatment of infants hospitalized with severe infectious diarrhea.

\section{Acknowledgments}

We are grateful to the Zambon Laboratory (São Paulo, SP, Brazil) for providing polymyxin and placebo for this study.

\section{References}

1. WHO (World Health Organization). Diarrhoeal Diseases Control Programme. Persistent diarrhoea in children in development countries. Report of a WHO Meeting. Bull World Health Organ 1988; 66: 709-717.

2. WHO (World Health Organization). Evaluation of an algorithm for the treatment of persistent diarrhea: a multicentre study. Bull World Health Organ 1996; 74: 479-489.

3. Victora CG, Huttly SR, Fuchs SC, Nobre LC, Barros FC. Deaths due to dysentery, acute and persistent diarrhoea among Brazilian infants. Acta Paediatr Suppl 1992; 381: 7-11.

4. WHO (World Health Organization). Persistent diarrhoea and breastfeeding. WHO/CHD/97.8. Geneva: World Health Organization; 1997.

5. Fagundes Neto U, Ferreira VC, Patricio FR, Mostaco VL, Trabulsi LR. Protracted diarrhea: the importance of the enteropathogenic $E$. coli (EPEC) strains and Salmonella in its genesis. J Pediatr Gastroenterol Nutr 1989; 8: 207-211.

6. Gomes TA, Rassi V, MacDonald KL, Ramos SR, Trabulsi LR, Vieira
MA, et al. Enteropathogens associated with acute diarrheal disease in urban infants in São Paulo, Brazil. J Infect Dis 1991; 164: 331337.

7. Scaletsky IC, Pedroso MZ, Oliva CA, Carvalho RL, Morais MB, Fagundes-Neto U. A localized adherence-like pattern as a second pattern of adherence of classic enteropathogenic Escherichia coli to HEp-2 cells that is associated with infantile diarrhea. Infect Immun 1999; 67: 3410-3415.

8. Fagundes Neto U, Schmitz LG, Scaletsky I. Clinical and epidemiological characteristics of acute diarrhea by classical enteropathogenic Escherichia coli. Rev Assoc Med Bras 1995; 41: 259-265.

9. Franzolin MR, Alves RC, Keller R, Gomes TA, Beutin L, Barreto ML, et al. Prevalence of diarrheagenic Escherichia coli in children with diarrhea in Salvador, Bahia, Brazil. Mem Inst Oswaldo Cruz 2005; 100: 359-363.

10. Orlandi PP, Magalhaes GF, Matos NB, Silva T, Penatti M, Nogueira $\mathrm{PA}$, et al. Etiology of diarrheal infections in children of Porto Velho 
(Rondonia, Western Amazon region, Brazil). Braz J Med Biol Res 2006; 39: 507-517.

11. da Cruz AS, Fagundes Neto U. Influence of classic enteropathogenic Escherichia coli on small bowel bacterial proliferation in infant's acute and persistent diarrhea. Rev Assoc Med Bras 1996; 42: 8994.

12. Alam NH, Bardhan PK, Haider R, Mahalanabis D. Trimethoprimsulphamethoxazole in the treatment of persistent diarrhoea: a double blind placebo controlled clinical trial. Arch Dis Child 1995; 72: 483486.

13. Davidson G, Barnes G, Bass D, Cohen M, Fasano A, Fontaine O, et al. Infectious diarrhea in children: Working Group Report of the First World Congress of Pediatric Gastroenterology, Hepatology, and Nutrition. J Pediatr Gastroenterol Nutr 2002; 35 (Suppl 2): S143S150.

14. Hill ID, Mann MD, Househam KC, Bowie MD. Use of oral gentamicin, metronidazole, and cholestyramine in the treatment of severe persistent diarrhea in infants. Pediatrics 1986; 77: 477-481.

15. Bartlett AV, Torun B, Morales C, Cano F, Cruz JR. Oral gentamicin is not effective treatment for persistent diarrhea. Acta Paediatr Suppl 1992; 381: 149-154.

16. Bhatnagar S, Bhan MK, Sazawal S, Gupta U, George C, Arora NK, et al. Efficacy of massive dose oral gentamicin therapy in nonbloody persistent diarrhea with associated malnutrition. $J$ Pediatr Gastroenterol Nutr 1992; 15: 117-124.

17. Bergan T, Fuglesang J. Polymyxin antibiotics: chemical and pharmacokinetic properties. Antibiot Chemother 1982; 31: 119-144.

18. Hazenberg MP, Pennock-Schroder AM, Van de Merwe JP. Reversible binding of polymyxin $\mathrm{B}$ and neomycin to the solid part of faeces. J Antimicrob Chemother 1986; 17: 333-339.

19. Rosner B. Fundamentals of biostatistics. 4th edn. Belmount: Duxbury Press; 1995.

20. OMS (Organización Mundial de la Salud). Tratamiento y prevención de la diarrea aguda (Pautas Práticas). Geneva: Organización Mundial de la Salud; 1989.

21. Kleinman RE, Galeano NF, Ghishan F, Lebenthal E, Sutphen J, Ulshen $\mathrm{MH}$. Nutritional management of chronic diarrhea and/or malabsorption. J Pediatr Gastroenterol Nutr 1989; 9: 407-415.

22. Dean AG, Dean JA, Coulombier D, Brendel KA, Smith DC, Burton $\mathrm{AAH}$, et al. Epi-Info. Version 6.0: a word processor database and statistics program for epidemiology on microcomputers. Atlanta: Center of Disease Control and Prevetion; 1994.

23. WHO (World Health Organization). Measuring change in nutritional status: guideliness for assessing the nutritional impact of supplementary feeding programs to vulnerable groups. Geneva: World Health Organization; 1983.

24. Lennete EH, Balows A, Hausler WS Jr, Shadomy HJ. Manual of clinical microbiology. 4th edn. Washington: ASM - Americam Society for Microbiology; 1985.
25. Holdeman LN, Moore WEC. Anaerobe laboratory manual. 4th edn. Virginia: Virginia Polytechnic Institute and State University; 1977.

26. National Committee for Clinical Laboratory Standards. Disk diffusion. Supplemental tables. M 100-S 10 (M2). Wayne: NCCLS; 2000.

27. Sambourg M, Goudeau A, Courant C, Pinon G, Denis F. Direct appraisal of latex agglutination testing, a convenient alternative to enzyme immunoassay for the detection of rotavirus in childhood gastroenteritis, by comparison of two enzyme immunoassays and two latex tests. J Clin Microbiol 1985; 21: 622-625.

28. Vallada EP. Manual de exames de fezes. Coprologia e parasitologia. São Paulo: Livraria Atheneu Editora; 1993.

29. Henriksen SA, Pohlenz JF. Staining of cryptosporidia by a modified Ziehl-Neelsen technique. Acta Vet Scand 1981; 22: 594-596.

30. Kamath KR, Murugasu R. A comparative study of four methods for detecting Giardia lamblia in children with diarrheal disease and malabsorption. Gastroenterology 1974; 66: 16-21.

31. Fagundes-Neto U, Reis MH, Wehba J, Silvestrini WS, Trabulsi LR. Small bowel bacterial flora in normal and in children with acute diarrhea. Arq Gastroenterol 1980; 17: 103-108.

32. Bardhan PK, Albert MJ, Alam NH, Faruque SM, Neogi PK, Mahalanabis D. Small bowel and fecal microbiology in children suffering from persistent diarrhea in Bangladesh. $J$ Pediatr Gastroenterol Nutr 1998; 26: 9-15.

33. Toledo MRF, Fontes CF, Trabulsi LR. MILi: um meio para realização dos testes de motilidade, indol e lisina descarboxilase. Rev Microbiol 1982; 13: 230-235.

34. Hill ID, Mann MD, Moore L, Bowie MD. Duodenal microflora in infants with acute and persistent diarrhoea. Arch Dis Child 1983; 58 : 330-334.

35. da Cruz AS, Fagundes-Neto U. Simple and rapid technique of intubation for collection of jejunal secretions. Arq Gastroenterol 1993; 30: 69-72.

36. Fox E. User's Manual - Sigma Stat: Statistical Software for Windows. Berlim: Jandel; 1994.

37. Huang DB, DuPont HL. Enteroaggregative Escherichia coli: an emerging pathogen in children. Semin Pediatr Infect Dis 2004; 15: 266-271.

38. Fagundes-Neto $U$, Scaletsky IC. The gut at war: the consequences of enteropathogenic Escherichia coli infection as a factor of diarrhea and malnutrition. São Paulo Med J 2000; 118: 21-29.

39. Thoren A, Wolde-Mariam T, Stintzing G, Wadstrom T, Habte D. Antibiotics in the treatment of gastroenteritis caused by enteropathogenic Escherichia coli. J Infect Dis 1980; 141: 27-31.

40. Bhutta ZA, Ghishan F, Lindley K, Memon IA, Mittal S, Rhoads JM. Persistent and chronic diarrhea and malabsorption: Working Group report of the second World Congress of Pediatric Gastroenterology, Hepatology, and Nutrition. J Pediatr Gastroenterol Nutr 2004; 39 (Suppl 2): S711-S716. 